COSTA, N.L., GIANLUPPI, V. e MORAES, A. Avaliação da rebrota natural de Axonopus aureus em pastagens nativas dos lavrados de Roraima. PUBVET, Londrina, V. 5, N. 24, Ed. 171, Art. $1151,2011$.

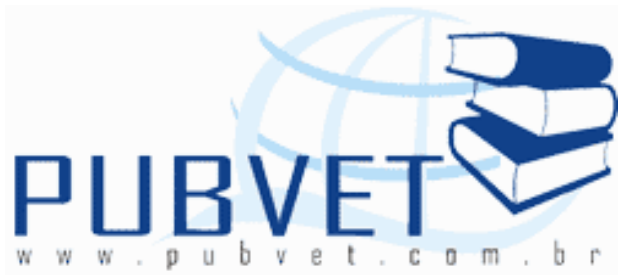

PUBVET, Publicações em Medicina Veterinária e Zootecnia.

\title{
Avaliação da rebrota natural de Axonopus aureus em pastagens nativas dos lavrados de Roraima
}

\author{
Newton de Lucena Costa ${ }^{1}$, Vicente Gianluppi ${ }^{2}$, Aníbal de Moraes $^{3}$
}

${ }^{1}$ Eng. Agr., M.Sc., Embrapa Roraima, Boa Vista Roraima. Doutorando em Agronomia/Produção Vegetal, UFPR, Curitiba, Paraná. E-mail:

newton@cpafrr.embrapa.br

${ }^{2}$ Eng. Agr., M.Sc., Embrapa Roraima, Boa Vista, Roraima

${ }^{3}$ Eng. Agr., D.Sc., Professor Associado II, Universidade Federal do Paraná, Curitiba, Paraná.

\section{Resumo}

Avaliou-se a rebrota natural de Axonopus aureus em pastagens nativas dos lavrados de Roraima, no início do período chuvoso. Os parâmetros mensurados foram rendimento de forragem e características morfogênicas e estruturais da gramínea. Os tratamentos consistiram de quatro idades das plantas $(21,35$, 49 e 63 dias decorridos o início do período chuvoso). O delineamento experimental foi inteiramente casualizado com quatro repetições. As avaliações foram realizadas no período de junho a agosto de 2009. Os rendimentos de matéria seca verde e total, número total de perfilhos/planta, número de perfilhos axilares, número de perfilhos vivos e área foliar foram diretamente proporcionais às idades das plantas, ocorrendo o inverso quanto à taxa de aparecimento e de expansão de folhas, enquanto que os rendimentos de 
COSTA, N.L., GIANLUPPI, V. e MORAES, A. Avaliação da rebrota natural de Axonopus aureus em pastagens nativas dos lavrados de Roraima. PUBVET, Londrina, V. 5, N. 24, Ed. 171, Art. $1151,2011$.

matéria seca morta não foram afetados. Considerando-se a baixa disponibilidade de matéria seca verde de $A$. aureus, recomenda-se a utilização de alguma prática de manejo, preferencialmente o pastejo ou a roçagem, de modo a remover o material morto e de baixo valor nutritivo e permitir uma rebrota mais vigorosa da gramínea no início do período chuvoso.

Palavras-chave: idade da planta, matéria seca, folhas, morfogênese

\title{
Evaluation of natural regrowth of Axonopus aureus in a native pasture of Roraima's Savannas
}

\begin{abstract}
The natural regrowth of Axonopus aureus in native pasture of Roraima's savannas was evaluated, during early rainy period. The parameters measured were dry matter (DM) yields and grass morphogenetic and structural characteristics. The experimental design was a completely randomized, with four replications. The treatments consisted of four cutting plants age $(21,35$, 49 and 63 days after beginning of the rainy period). Evaluations were carried out during the period of June to August of 2009. The green and total DM, number of tillers/plant, number of axillary tillers/plant, number of live tillers/plant, number of live leaves/tiller and leaf area were directly proportional to plant age. The leaf appearance and elongation rate were negatively affected by plant age, while the dead DM was not affected by plant age. Considering the low green DM availability of $A$. aureus, its recommends the utilization of some management practice, preferentially grazing or mowing, to remove the dead DM with low nutrition value and permit a grass vigorous regrowth in the beginning of the rainy period.
\end{abstract}

Keywords: plant age, dry matter, leaves, morphogenesis

\section{Introdução}

As pastagens nativas dos lavrados de Roraima, apesar de limitações quantitativas e qualitativas, historicamente, proporcionaram 0 suporte 
COSTA, N.L., GIANLUPPI, V. e MORAES, A. Avaliação da rebrota natural de Axonopus aureus em pastagens nativas dos lavrados de Roraima. PUBVET, Londrina, V. 5, N. 24, Ed. 171, Art. $1151,2011$.

alimentar para a exploração pecuária, que passou a se constituir, ao longo dos anos, como a principal atividade econômica da região (COSTA et al., 2008). O sistema de pastejo contínuo com taxa de lotação variável, mas em geral extensivo a superextensivo e desvinculado do ritmo produtivo estacional, tem contribuição direta para os baixos índices produtivos dos rebanhos. Como forma de melhorar as condições de alimentação, os criadores usam o fogo, prática de manejo das pastagens visando à eliminação da forragem não consumida e endurecida, proporcionando melhoria no valor nutritivo quando em estados iniciais de crescimento, onde a gramínea se torna mais tenra (BRAGA, 1998). Nas pastagens nativas dos lavrados, onde a gramínea Axonopus aureus constitui 30 a 45\% de sua composição botânica, a produção animal pode ser muito baixa, o que inviabiliza economicamente a atividade pecuária em áreas onde há sua predominância, desde que não sejam implementadas práticas para o seu melhoramento (GIANLUPPI et al., 2001).

$O$ fogo tem sido, ao longo dos anos, o único elemento de manejo e o grande selecionador das espécies de gramíneas nativas nesse ecossistema, sendo utilizado em até três vezes por ano, constituindo-se em importante fator ecológico da região, porém com reflexos altamente significativos e negativos no passivo ambiental decorrente da atividade pecuária (COSTA et al., 2008). Estudos realizados com diferentes tipos de pastagens nativas de regiões tropicais demonstraram os efeitos deletérios do fogo sobre as características físicas e químicas do solo, além de proporcionarem incrementos efêmeros e de baixa magnitude na produtividade e qualidade da forragem. Apesar de serem ecossistemas relativamente estáveis, as pastagens nativas, manejadas sob fogo, não possibilitam a obtenção de indicadores técnicos e ambientais que assegurem a sua sustentabilidade econômica, o que implica em uma exploração pecuária obsoleta e com poucas perspectivas de evolução. Para tanto, a adoção de práticas alternativas às queimadas surgem como ferramentas de manejo que podem substancialmente modificar e melhorar os sistemas tradicionais de exploração da pecuária na região. Deste modo, o conhecimento das características morfogenéticas e estruturais proporciona 
COSTA, N.L., GIANLUPPI, V. e MORAES, A. Avaliação da rebrota natural de Axonopus aureus em pastagens nativas dos lavrados de Roraima. PUBVET, Londrina, V. 5, N. 24, Ed. 171, Art. $1151,2011$.

uma visualização da curva estacional de produção de forragem e uma estimativa de sua qualidade (GOMIDE, 1997), além de permitir a proposição de práticas de manejo distintas específicas para cada gramínea forrageira (LEMAIRE, 2001).

Neste trabalho foram avaliadas a produtividade de forragem e as características estruturais e morfogênicas da rebrota natural de pastagens de Axonopus aureus, em diferentes idades de corte, no início do período chuvoso.

\section{Material e Métodos}

O ensaio foi conduzido no Campo Experimental da Embrapa Roraima, localizado em Boa Vista $\left(60^{\circ} 43^{\prime} 51^{\prime \prime}\right.$ de longitude oeste e $2^{\circ} 45^{\prime} 25^{\prime \prime}$ de latitude norte), durante o período de junho a agosto de 2009. O clima da região, segundo a classificação de Köppen, é Awi, caracterizado por períodos seco e chuvoso bem definido, com aproximadamente seis meses cada um. A precipitação anual é de $1.600 \mathrm{~mm}$, sendo que $80 \%$ ocorrem no período de Abril a Setembro. O solo da área experimental é um Latossolo Amarelo, textura média, com as seguintes características químicas, na profundidade de 0-20 cm: $\mathrm{P}=1,8 \mathrm{mg} / \mathrm{kg} ; \mathrm{pH}_{\mathrm{H} 2 \mathrm{O}}=4,8 ; \mathrm{Ca}=0,25 \mathrm{cmol}_{\mathrm{c}} \cdot \mathrm{dm}^{-3} ; \mathrm{Mg}=0,65$ $\mathrm{cmol}_{\mathrm{C}} \cdot \mathrm{dm}^{-3} ; \mathrm{K}=0,01 \mathrm{cmol}_{\mathrm{c}} \cdot \mathrm{dm}^{-3} ; \mathrm{Al}=0,61 \mathrm{cmol}_{\mathrm{C}} \mathrm{dm}^{-3} ; \mathrm{H}+\mathrm{Al}=2,64 \mathrm{cmol}_{\mathrm{c}} \cdot \mathrm{dm}^{-}$ 3; $\mathrm{SB}=0,91 \mathrm{cmol}_{\mathrm{c}} \cdot \mathrm{dm}^{-3} ; \mathrm{CTC}=3,6 \mathrm{cmol}_{\mathrm{c}} \cdot \mathrm{dm}^{-3} ; \mathrm{V}(\%)=25,6 \mathrm{e} \mathrm{m}(\%)=40$.

O delineamento experimental foi inteiramente casualizado com quatro repetições, sendo os tratamentos constituídos por quatro idades de corte (21, 35, 49 e 63 dias decorridos o início do período chuvoso). Cada unidade experimental foi representada por uma parcela com 2,0 $\mathrm{m}^{2}$, sendo a área útil de $1,0 \mathrm{~m}^{2}$. As avaliações foram realizadas em uma pastagem que não foi submetida à métodos físico (queima), mecânico (roçagem) ou biológico (pastejo) para o seu rebaixamento, no final do período seco.

Os parâmetros avaliados foram rendimento de matéria seca morta (MSM), matéria seca verde (MSV), matéria seca total (MST), número total de perfilhos/planta (NTP), número de perfilhos axilares (NPA), número de perfilhos vivos (NPV), número de folhas vivas/perfilho (NFV), área foliar (AF), 
COSTA, N.L., GIANLUPPI, V. e MORAES, A. Avaliação da rebrota natural de Axonopus aureus em pastagens nativas dos lavrados de Roraima. PUBVET, Londrina, V. 5, N. 24, Ed. 171, Art. $1151,2011$.

taxa de aparecimento de folhas (TAF) e taxa de expansão foliar (TEF). Com exceção dos rendimentos de MS que foram determinados em toda a área útil da parcela, para as demais variáveis, as avaliações foram realizadas em quatro touceiras/parcela, selecionadas em função de suas alturas e diâmetros, de modo a representar a variabilidade da população de plantas em cada parcela. A TAF, TEF e AF foram determinadas apenas nos perfilhos vivos. A TAF e a TEF foram calculadas dividindo-se o comprimento acumulado de folhas e o número total de folhas no perfilho, respectivamente, pelo período de rebrota. Para o cálculo da AF utilizou-se a fórmula da área do triângulo (altura $\times$ base/2) e, para tanto foram anotados o comprimento e a largura de todas as folhas dos perfilhos amostrados.

\section{Resultados e Discussão}

Os rendimentos de MSM não foram afetados $(P>0,05)$ pelas idades de corte, sendo a disponibilidade média de forragem de $2.209 \mathrm{~kg} / \mathrm{ha}$. A MSV e a MST foram positiva e linearmente incrementadas pelas idades de corte, sendo as relações descritas pelas equações: $Y=210,1+7,6286 \times\left(r^{2}=0,97\right)$ e $Y=$ $1.951,1+18,7786 \times\left(r^{2}=0,95\right)$, respectivamente (Tabela 1$)$. Estes valores são inferiores aos reportados por Heringer e Jacques (2002) para pastagens nativas do Rio Grande do Sul manejadas na ausência de fogo ou roçagem (3.025 kg/ha). Contudo, em ambas as situações a disponibilidade de forragem, apesar de satisfatória em termos quantitativos, caracteriza-se por baixo valor nutritivo, como conseqüência da elevada proporção de folhas senescentes e, dificilmente seria consumida pelos animais, face aos seus elevados teores de fibra e baixa concentração de nutrientes. A maioria das gramíneas nativas dos lavrados de Roraima apresenta alta retenção de folhas senescidas, o que pode afetar de forma negativa os processos de reciclagem de nutrientes, tornandose necessário a utilização de alguma prática de manejo, preferencialmente o pastejo ou a roçagem, de modo a favorecer uma rebrota rápida e vigorosa, constituída de forragem de alto valor nutritivo e de grande aceitabilidade pelos animais. Apesar do efeito negativo sobre a qualidade da forragem, a 
COSTA, N.L., GIANLUPPI, V. e MORAES, A. Avaliação da rebrota natural de Axonopus aureus em pastagens nativas dos lavrados de Roraima. PUBVET, Londrina, V. 5, N. 24, Ed. 171, Art. $1151,2011$.

senescência representa um importante processo fisiológico no fluxo de tecidos da gramínea, pois cerca de $50 \%$ do carbono e $80 \%$ do nitrogênio podem ser reciclados das folhas senescentes e utilizados pela planta para a produção de novos tecidos foliares (CARRÈRE et al., 1997; LEMAIRE; AGNUSDEI, 2000).

Considerando-se uma eficiência de utilização da forragem disponível de $50 \%$ e um consumo médio diário de $11,25 \mathrm{~kg}$ de MS/UA (UA $=450 \mathrm{~kg}$ de peso vivo), o qual representa $2,5 \%$ do peso vivo do animal (COSTA, 2004), a disponibilidade de MSV registrada neste trabalho proporcionaria períodos de pastejo de 34,$6 ; 38,8 ; 54,0$ e 61,2 dias, respectivamente para idades de corte de 21, 35, 49 e 63 dias. Mochiutti et al. (1999), avaliando a disponibilidade de forragem de pastagens nativas dos cerrados do Amapá, submetidas à queima anual, bienal ou roçagem, estimaram rendimentos de $1.302 ; 1.493$ e 1.353 $\mathrm{kg} / \mathrm{ha}$ de MS, respectivamente, os quais foram inferiores aos obtidos neste trabalho.

Tabela 1. Rendimento de matéria seca morta (MSM), matéria seca verde (MSV), matéria seca total (MST), número total de perfilhos/planta (NTP), número de perfilhos axilares (NPA), número de perfilhos vivos (NPV) e número de folhas vivas/perfilho (NFV) de Axonopus aureus, em função da idade das plantas.

\begin{tabular}{cccccccc}
\hline $\begin{array}{c}\text { Idade } \\
\text { (dias) }\end{array}$ & MSM & MSV & MST & NTP & NPA & NPV & NFV \\
\hline 21 & $1.975 \mathrm{a}$ & $389 \mathrm{~b}$ & $2.364 \mathrm{c}$ & $12,55 \mathrm{c}$ & $3,21 \mathrm{c}$ & $3,88 \mathrm{~b}$ & $2,89 \mathrm{c}$ \\
35 & $2.103 \mathrm{a}$ & $437 \mathrm{~b}$ & $2.540 \mathrm{c}$ & $15,02 \mathrm{c}$ & $4,49 \mathrm{bc}$ & $5,02 \mathrm{~b}$ & $4,07 \mathrm{~b}$ \\
49 & $2.344 \mathrm{a}$ & $608 \mathrm{a}$ & $2.952 \mathrm{~b}$ & $18,78 \mathrm{~b}$ & $6,01 \mathrm{ab}$ & $6,35 \mathrm{a}$ & $4,88 \mathrm{a}$ \\
63 & $2.415 \mathrm{a}$ & $688 \mathrm{a}$ & $3.103 \mathrm{a}$ & $23,11 \mathrm{a}$ & $7,19 \mathrm{a}$ & $6,86 \mathrm{a}$ & $5,31 \mathrm{a}$ \\
\hline
\end{tabular}

- Médias seguidas de mesma letra não diferem entre si $(P>0.05)$ pelo teste de Tukey

O NTP, NPA e NPV foram diretamente proporcionais às idades de corte, sendo estimados, respectivamente, pelas equações: $Y=6,733+0,2531 \times\left(r^{2}\right.$ $=0,94), Y=1,187+0,0961 \times\left(r^{2}=0,93\right)$ e $Y=2,446+0,0734 \times\left(r^{2}=\right.$ 0,96). A correlação entre o NPV e o rendimento de MSV foi positiva e significativa ( $r=0,9749 ; P=0,0081)$, a qual explicou em $95 \%$ os incrementos verificados nos rendimentos de forragem da gramínea, em função das idades de corte (Tabela 1). Em termos percentuais, a participação dos perfilhos vivos 
COSTA, N.L., GIANLUPPI, V. e MORAES, A. Avaliação da rebrota natural de Axonopus aureus em pastagens nativas dos lavrados de Roraima. PUBVET, Londrina, V. 5, N. 24, Ed. 171, Art. $1151,2011$.

representou apenas 30,$9 ; 33,4 ; 33,8$ e $29,7 \%$ do NTP, respectivamente para plantas aos 21, 35, 49 e 63 dias de rebrota, o que contribui de forma significativa para a baixa disponibilidade de MSV. O baixo NPA evidencia que não houve remoção dos meristemas apicais, seja pelo pastejo ou roçagem, de modo que a predominância dos perfilhos basilares sobre os axilares não foi suprimida. A relação entre NFV e as idades de corte foi ajustada ao modelo linear de regressão e descrita pela equação: $Y=1,866+0,0576 \times\left(r^{2}=\right.$ $0,97)$ (Tabela 1). A AF foi diretamente proporcional às idades das plantas, ocorrendo o inverso para a TAF e a TEF. As relações foram significativas $(P<0,05)$ e ajustadas ao modelo linear de regressão, sendo descritas pelas equações $Y=0,3895+0,0236 \times\left(r^{2}=0,96\right) ; Y=0,1474-0,0008 \times\left(r^{2}=\right.$ $0,95)$ e $Y=2,2321-0,0124 \times\left(r^{2}=0,92\right)$, respectivamente para AF, TAF e TEF (Tabela 2). Os valores deste trabalho, em todas as idades de corte, foram inferiores aos reportados por Costa et al. (2008), avaliando A. aureus, que estimaram valores médios de 0,1597 folhas/perfilho/dia; 2,11 cm/dia/perfilho e $7,08 \mathrm{~cm}^{2} /$ perfilho, para plantas aos 45 dias de rebrota.

Tabela 2. Área foliar, taxa de aparecimento foliar e taxa de expansão foliar de Axonopus aureus, em função da idade das plantas.

\begin{tabular}{cccc}
\hline $\begin{array}{c}\text { Idade } \\
\text { (dias) }\end{array}$ & $\begin{array}{c}\text { Área Foliar } \\
\text { cm²/perfilho }\end{array}$ & $\begin{array}{c}\text { Taxa de Aparecimento Foliar } \\
\text { folhas/dia/perfilho }\end{array}$ & $\begin{array}{c}\text { Taxa de Expansão Foliar } \\
\text { cm/dia/perfilho }\end{array}$ \\
\hline 21 & $0,82 \mathrm{c}$ & $0,138 \mathrm{a}$ & $1,95 \mathrm{a}$ \\
35 & $1,29 \mathrm{~b}$ & $0,116 \mathrm{~b}$ & $1,83 \mathrm{a}$ \\
49 & $1,60 \mathrm{a}$ & $0,099 \mathrm{~b}$ & $1,62 \mathrm{~b}$ \\
63 & $1,82 \mathrm{a}$ & $0,108 \mathrm{~b}$ & $1,44 \mathrm{c}$ \\
\hline
\end{tabular}

- Médias seguidas de mesma letra não diferem entre si $(P>0.05)$ pelo teste de Tukey

\section{Conclusões}

Os rendimentos de MSV, MST, NTP, NPA, NPV, NFV e AF foram diretamente proporcionais às idades das plantas, ocorrendo o inverso quanto à TAF e TEF, enquanto que os rendimentos de MSM não foram afetados. Considerando-se a baixa disponibilidade de MSV de $A$. aureus, recomenda-se a utilização de alguma prática de manejo, preferencialmente o pastejo, de modo 
COSTA, N.L., GIANLUPPI, V. e MORAES, A. Avaliação da rebrota natural de Axonopus aureus em pastagens nativas dos lavrados de Roraima. PUBVET, Londrina, V. 5, N. 24, Ed. 171, Art. $1151,2011$.

a remover o material morto e de baixo valor nutritivo e permitir uma rebrota mais vigorosa da gramínea no início do período chuvoso.

\section{Referências Bibliográficas}

BRAGA, R.M. A agropecuária em Roraima: considerações históricas, de produção e geração de conhecimento. Boa Vista: Embrapa Roraima, 1998. 63p. (Embrapa Roraima. Documentos, 1).

CARRÈRE, P.; LOUAULT, F.; SOUSSANA, J.F. Tissue turnover within grass-clover mixed swards grazed by sheep: methodology for calculating growth, senescence and intake fluxes. Journal of Applied Ecology, v.34, p.333-348, 1997.

COSTA, N. de L.; MATTOS, P.S.R.; BENDAHAN, A.B. et al. Morfogênese de duas gramíneas forrageiras nativas dos lavrados de Roraima. Pubvet, v.2, n.43, Art\#410, 2008.

COSTA, N. de L. Formação, manejo e recuperação de pastagens em Rondônia. Porto Velho: Embrapa Rondônia, 2004. 217p.

GIANLUPPI, D.; GIANLUPPI, V.; SMIDERLE, O. Produção de pastagens no cerrado de Roraima. Boa Vista: Embrapa Roraima, 4p. 2001. (Embrapa Roraima. Comunicado Técnico, 14)

GOMIDE, J.A. Morfogênese e análise de crescimento de gramíneas tropicais. In: SIMPÓSIO INTERNACIONAL SOBRE PRODUÇÃO ANIMAL EM PASTEJO, Viçosa, 1997. Anais... Viçosa: UFV, 1997. p.411-430.

HERINGER, E.; JACQUES, A.V.A. Acumulação de forragem e material morto em pastagem nativa sob distintas alternativas de manejo em relação às queimadas. Revista Brasileira de Zootecnia, v.31, n.3, p.599-604, 2002.

LEMAIRE, G. Ecophysiological of grasslands: Dynamics aspects of forage plant population in grazed swards. In: INTERNATIONAL GRASSLAND CONGRESS, 19., 2001, São Paulo, Proceedings... São Paulo: ESALQ, 2001, p.29-37.

LEMAIRE, G.; AGNUSDEI, M. Leaf tissue turnover and efficiency of herbage utilization. In: LEMAIRE, G.; HODGSON, J.; MORAES, A. et al. (Eds). Grassland ecophysiology and grazing ecology. London: CAB International, 2000. p.265-288.

MOCHIUTTI, S.; MEIRELLES, P.R.L.; SOUZA FILHO, A.P. Efeito da freqüência e época de roçada sobre a produção e rendimentos das espécies de pastagem nativa de cerrado do Amapá. In: REUNIÃO ANUAL DA SOCIEDADE BRASILEIRA DE ZOOTECNIA, 36., 1999, Porto Alegre. Anais... Porto Alegre: SBZ, 1999. 3p. (CD-ROM). 